\title{
Complete remission of diffuse hepatocellular carcinoma in a young adult after GSP-TACE: a case report
}

\author{
Song Liu, Yuewei Zhang ${ }^{*}$, Guangsheng Zhao and Ying Liu
}

\begin{abstract}
Hepatocellular carcinoma (HCC) is the most common primary tumor of the liver. It mostly occurs in older age groups (usually those 50 to 60 years old), and rarely in young adults. The survival rate of these young HCC patients is usually very low. The authors report a case of a 22-year old man with diffuse-type HCC who successfully achieved complete remission for 46 months after second transcatheter arterial chemoembolization using gelatin sponge particles (Eric Kang Pharmaceutical Technology Co., Ltd. Hangzhou, China) combined with pirarubicin.
\end{abstract}

Keywords: gelatin sponge particles, hepatocellular carcinoma, transcatheter arterial chemoembolization, young adults

\section{Background}

Hepatocellular carcinoma (HCC) is a common malignancy worldwide, especially in South East Asia and Africa [1] and is the most common primary tumor of the liver $[2,3]$. Hepatocellular carcinoma can be classified into three types based on gross morphological characteristics: nodular, massive, or diffuse [4]. Although the nodular and massive types constitute the majority of HCC lesions, diffuse-type HCC still accounts for 7 to $13 \%$ of cases [5,6]. Worldwide, HCC mostly occurs in older age groups (usually 50 to 60 years old), and rarely in young adults [7]. However, the age distribution of patients with HCC differs substantially in different parts of the world. In Africa, HCC often affects young people, with $40 \%$ of those afflicted being under the age of 30 [8]. In China, it is relatively rare for people under 35 years old to have HCC. The survival rate of these young HCC patients is usually very low [9]. Compared with adult HCC, morphologically the tumor is often massive, diffused, with quicker growth, stronger invasiveness, and poor prognosis [10]. Diffusetype HCC almost always presents an advanced infiltrative tumor, so surgery is rarely indicated; rather, locoregional therapy in the form of transcatheter arterial

\footnotetext{
* Correspondence: zhangyuewei1121@163.com

Department of Interventional Radiology, Affiliated Zhongshan Hospital of Dalian University, Dalian, P.R. China
}

chemoembolization (TACE) is generally the only available therapeutic option [11].

In this case, we performed TACE using gelatin sponge particles (GSPs) to treat a 22-year-old patient with diffusetype hepatocellular carcinoma, and achieved complete remission. At the most recent follow-up, our patient had complete remission for 46 months after the second treatment, without any clinical disease recurrence.

\section{Case presentation}

A 22-year old male patient presented at our hospital with a 3-month history of acute onset of abdominal pain in July 2009. Contrast-enhanced abdominal magnetic resonance imaging (MRI) revealed more than 100 liver lesions, with the largest having a diameter of about $1.55 \mathrm{~cm}$ (Figure 1a). Laboratory results revealed a total bilirubin level of $26 \mu \mathrm{mol} / \mathrm{l}$, albumin level of $51 \mathrm{~g} / \mathrm{l}$, alanine transaminase level of $38 \mathrm{IU} / \mathrm{l}$ and $\alpha$-fetoprotein (AFP) level of $4,773 \mathrm{ng} / \mathrm{ml}$. The patient had a history of chronic hepatitis B infection for 4 years. The clinical diagnosis was hepatocellular carcinoma (diffuse-type). The status of the patient was graded as Child-Pugh class A, with an Eastern Cooperative Oncology Group (ECOG) Performance Status of 0, and was classified by the Barcelona Clinic Liver Cancer (BCLC) system as stage B. Curative treatments, such as surgery or radiofrequency ablation, were not possible, owing to the extent of 

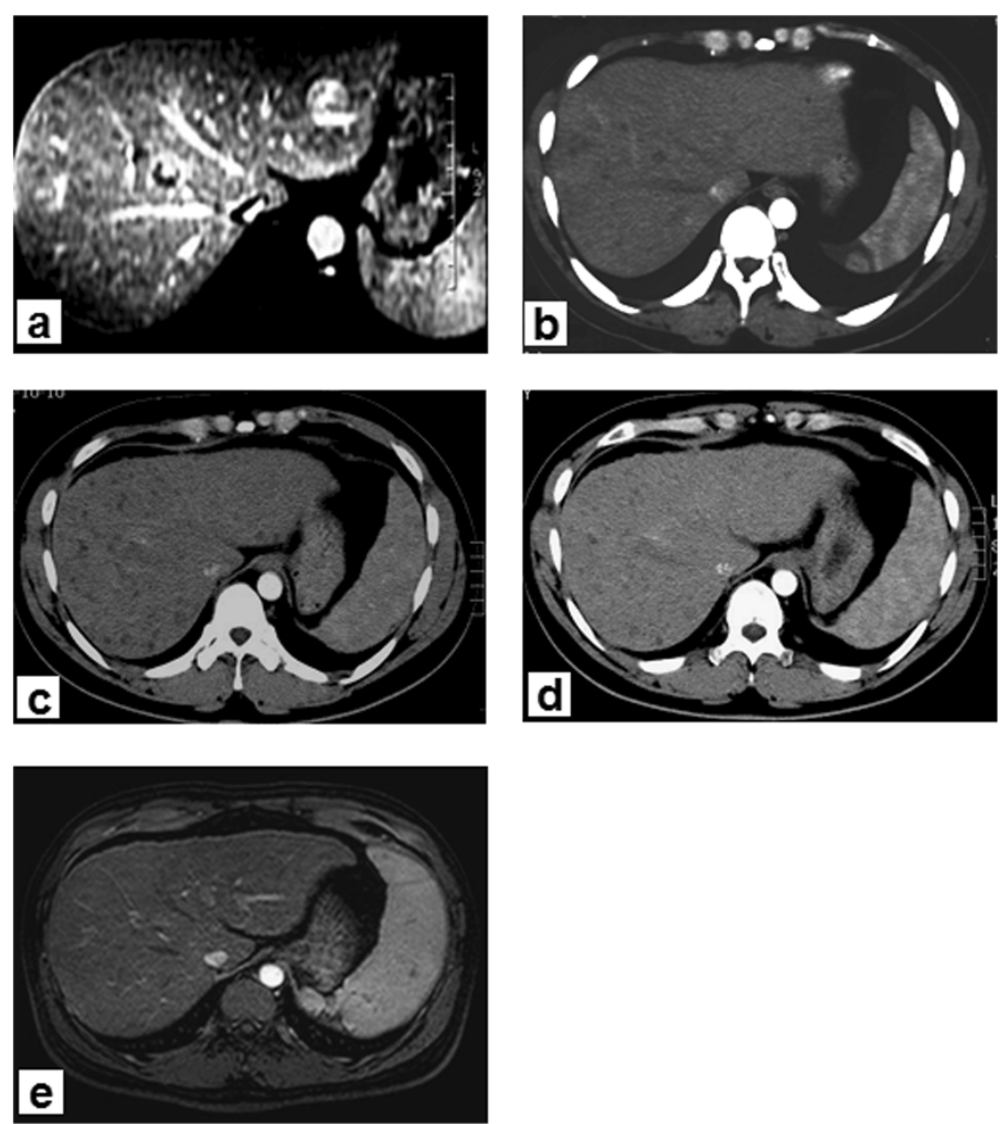

Figure 1 Abdominal computed tomography (CT) or magnetic resonance imaging (MRI). (a) Abdominal dynamic enhanced MRI obtained before treatment shows multiple liver lesions, the number of nodules $>100$, the largest diameter was about $1.55 \mathrm{~cm} ; \mathrm{AFP}$ level, 4,773 $\mathrm{ng} / \mathrm{ml}$. (b) CT scan obtained 2 months after the start of treatment showed that the lesion was not enhanced in the arterial phase; AFP level, $3.79 \mathrm{ng} / \mathrm{ml}$. (c) CT scan obtained 15 months after the start of treatment showed that the number of low-density lesions was less than before, also no enhancement; AFP level, $3.63 \mathrm{ng} / \mathrm{ml}$. (d) CT scan obtained 21 months after the start of treatment showed that the diffuse liver lesions disappeared, no abnormal enhancement lesions; AFP level, $2.26 \mathrm{ng} / \mathrm{ml}$. (e) MRI scan obtained 46 months after the second treatment showed that there were still no lesions in the liver; AFP, level $3.73 \mathrm{ng} / \mathrm{ml}$.

the disease. Hence, TACE was performed with $30 \mathrm{mg}$ GSPs (350 to $560 \mu \mathrm{m}$ in diameter) mixed with chemotherapeutic agent pirarubicin, $10 \mathrm{mg}$ ). As the nodules were scattered throughout the liver, we performed complete embolization of both hepatic arteries (Figure 2b). One month later, contrast-enhanced abdominal computed tomography $(\mathrm{CT})$ showed significant necrosis of the tumor, mostly without any enhancement in the arterial phase. The patient's AFP level decreased to $34.4 \mathrm{ng} / \mathrm{ml}$. Once again, TACE was performed with a supersolution of $30 \mathrm{mg}$ GSPs and $10 \mathrm{mg}$ pirarubicin. One month later, contrast-enhanced $\mathrm{CT}$ showed no enhancement in the arterial phase (Figure 1b). The patient's AFP level was $3.79 \mathrm{ng} / \mathrm{ml}$. Since then, AFP levels obtained from testing every one to two months, have been within the normal range (Figure 3). In addition, contrast-enhanced CT was also performed every 3 to 6 months, and showed that the lesions gradually reduced or disappeared with no new local tumor formation. During this period, the patient has been taking antiviral drugs (Lamivudine, $100 \mathrm{mg}$ once daily). At July 2013, the patient had been in complete remission for 46 months according to the modified Response Evaluation Criteria in Solid Tumors (RECIST).

\section{Discussion}

In China, $\mathrm{HCC}$ is rare in young adults and mostly occurs in men. In particular, diffuse-type HCC, when presented by young adults, has a typical clinical manifestation that includes high malignancy, lack of early diagnosis and poor prognosis $[10,12]$. In accordance with the BCLC clinical staging and treatment system [13], surgical resection is considered to be the primary treatment method. It is more suitable for patients with a single lesion of diameter less than $5 \mathrm{~cm}$, and normal total bilirubin levels without portal hypertension. Radiofrequency ablation is more limited to $<3$ localized lesions, with tumors $\leq 3 \mathrm{~cm}$ in diameter [14]. Liver transplantation is also considered as one of the curative methods; especially applicable to the 

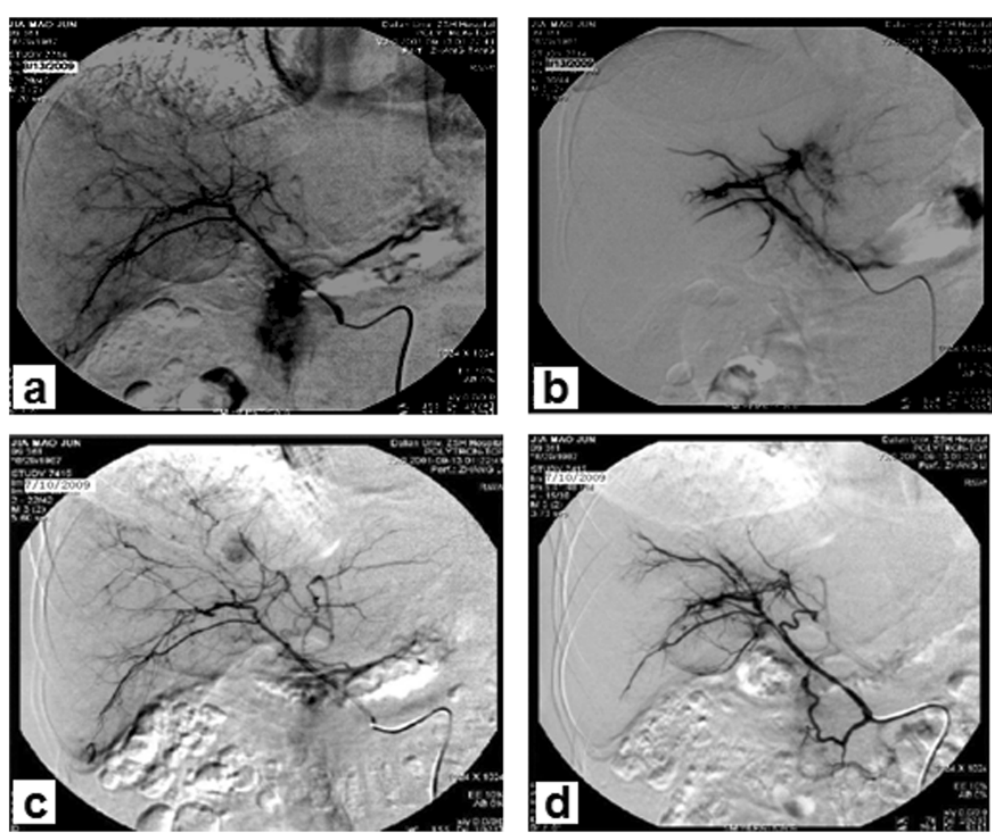

Figure 2 Hepatic artery angiography. (a) Hepatic arteriogram shows infiltrative tumor staining in the whole hepatic lobe. Transarterial chemoembolization was performed with a mixture of $30 \mathrm{mg}$ GSPs and $10 \mathrm{mg}$ pirarubicin. (b) After GSP embolization, digital subtraction angiography showed that the feeding artery of the tumor was completely blocked. (c) 1 month later, a follow-up angiogram shows almost complete disappearance of tumor vascularity. (d) A second and final GSP-TACE was performed. After that, the feeding artery of the tumor was completely blocked again.

patients who are not eligible for the abovementioned methods or where there is no improvement in the patient's condition [15]. It is also limited to localized lesions, single tumors with diameter less than $5 \mathrm{~cm}$ or multiple tumors numbering less than three tumors in total with diameters $\leq 3 \mathrm{~cm}$, according to Milan criteria [16]. Transcatheter arterial chemoembolization with lipiodol (lipiodol-TACE) is the standard treatment for unresectable intermediatestage HCC. However, different studies have shown an overall response rate of $17 \%$ to $61.9 \%$ and a complete tumor necrosis rate of only 0 to $4.8 \%$ [17-19].

The DC bead is an embolic drug-eluting bead that is used in the treatment of patients with both primary and

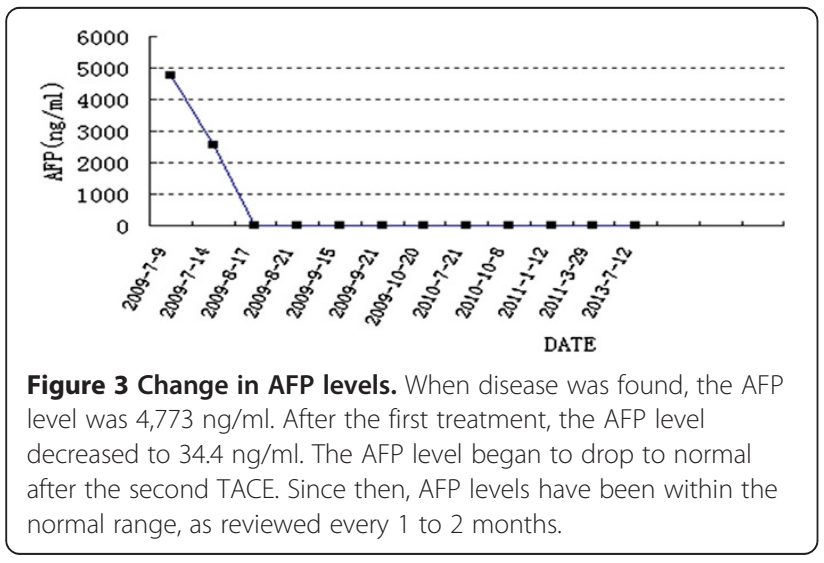

secondary liver cancers [20]. Compared with lipiodolTACE, using this embolization agent to perform TACE can gain higher tumor necrosis and lower postoperative complications [21]. However, DC beads are not available in China. This patient's cancer was not suitable for the use of permanent embolic agents, such as polyvinyl acetate or DC beads, as these require superselective embolization. The size of the lesions in this patient was $<3 \mathrm{~cm}$, and the lesions involved the whole liver. Transcatheter arterial infusion is the only suitable option for such patients. However, we chose GSPs as an alternative particulate embolic agent. The particle diameter is more suitable for use in blood vessels, and better suits the objective of delivering an embolic agent to block tumor target vessels regionally. As GSPs are absorbable particles that dissolve over time, the blocked artery can recanalize in about 2 weeks [22], ensuring the protection of postoperative liver function. In our recent study, we use GSPs to deal with a massive type of HCC, leading to a good efficacy and safety [23].

\section{Conclusions}

In this case, the patient was a young 22-year-old man in whom liver MRI suggested multiple grain-size lesions ( $>100$ nodules). Obviously, he was not a candidate for surgical resection and radiofrequency ablation, nor was liver transplantation indicated, according to the Milan criteria. However, how to acquire effective intervention and longterm survival is a clinical problem. We performed TACE 
with 350 to $560 \mu \mathrm{m}$ GSPs mixed with pirarubicin. There were no signs of acute liver failure and the liver function returned to normal after 7 days. The AFP level decreased to normal after the second TACE procedure. To date, the patient has been in complete remission for 46 months. The young man has just married, living a beatific life.

\section{Consent}

Written informed consent was obtained from the patient for publication of this case report and any accompanying images. A copy of the written consent is available for review by the editor-in-chief of this journal.

\section{Abbreviations \\ AFP: a-fetoprotein; BCLC: Barcelona Clinic Liver Cancer; CT: computed tomography; ECOG: Eastern Cooperative Oncology Group; GSP: gelatin sponge particle; HCC: hepatocellular carcinoma; MRI: magnetic resonance imaging; RECIST: Response Evaluation Criteria in Solid Tumors (RECIST); TACE: transcatheter arterial chemoembolization.}

\section{Competing interests}

The authors declare that they have no competing interests.

\section{Authors' contributions}

This treatment option was designed by YZ and SL. The treatment was administered by $Y Z$ and $S L$. The data analysis was performed by $S L, G Z, Y L$, and $Y Z$. YZ and SL wrote the manuscript.

\section{Acknowledgements}

None.

Received: 8 April 2014 Accepted: 11 June 2014

Published: 25 September 2014

\section{References}

1. Zeng Z, Ren J, O'Neil M, Zhao J, Bridges B, Cox J, Abdulkarim B, Schmitt TM, Kumer SC, Weinman SA: Impact of stem cell marker expression on recurrence of TACE-treated hepatocellular carcinoma post liver transplantation. BMC Cancer 2012, 12:584

2. Katyal S, Oliver JH 3rd, Peterson MS, Ferris JV, Carr BS, Baron RL: Extrahepatic metastases of hepatocellular carcinoma. Radiology 2000, 2169(3):698-703.

3. Anwar AM, Nosir YF, Chamsi-Pasha MA, Ajam A, Chamsipasha H: Right atrial metastasis mimicking myxoma in advanced hepatocellular carcinoma. Echocardiography 2010, 27(1):80-83.

4. Demirjian A, Peng P, Geschwind JF, Cosgrove D, Schutz J, Kamel IR, Pawlik TM: Infiltrating hepatocellular carcinoma: seeing the tree through the forest. J Gastrointest Surg 2011, 15:2089-2097.

5. Trevisani $F$, Caraceni $P$, Bernardi $M$, D'Intino $P E$, Arienti $V$, Amorati $P$, Stefanini GF, Grazi G, Mazziotti A, Fornalè L, Gozzetti G, Gasbarrini G. Gross pathologic types of hepatocellular carcinoma in Italian patients. Relationship with demographic, environmental, and clinical factors. Cancer 1993, 72:1557-1563.

6. Kanematsu M, Semelka RC, Leonardou P, Mastropasqua M, Lee JK: Hepatocellular carcinoma of diffuse type: MR imaging findings and clinical manifestations. J Magn Reson Imaging 2003, 18:189-195.

7. Hernández-Castillo E, Mondragón-Sánchez R, Garduno-Lopez AL, Gómez-Gómez E, Ruiz-Molina JM, Oñate-Ocaña LF, Bernal-Maldonado R: Hepatocellular carcinoma in the youth. A comparative analysis with hepatocellular carcinoma in adulthood. Hepatogastroenterology 2005, 52(63):903-907.

8. Aramaki M, Kawano K, Sasaki A, Ohno T, Tahara K, Kai S, Iwashita Y, Kitano S: Hepatocellular carcinoma in young adults. Hepatogastroenterology 2005, 52(66):1795-1797.

9. Yamazaki Y, Kakizaki S, Sohara N, Sato K, Takagi H, Arai H, Abe T, Katakai K Kojima A, Matsuzaki Y, Mori M: Hepatocellular carcinoma in young adults: the clinical characteristics, prognosis, and findings of a patient survival analysis. Dig Dis Sci 2007, 52:1103-1107.
10. Tsai HL, Liu CS, Chin TW, Wei CF: Hepatoblastoma and hepatocellular carcinoma in children. J Chin Med Assoc 2004, 67(2):83-88.

11. Kneuertz PJ, Demirjian A, Firoozmand A, Corona-Villalobos C, Bhagat N, Herman J, Cameron A, Gurakar A, Cosgrove D, Choti MA, Geschwind JF, Kamel IR, Pawlik TM: Diffuse infiltrative hepatocellular carcinoma: assessment of presentation, treatment, and outcomes. Ann Surg Oncol 2012, 19(9):2897-2907.

12. Yang JD, Roberts $L$ : Epidemiology and management of hepatocellular carcinoma. Infect Dis Clin North Am 2010, 24:899-919.

13. Llovet JM, Bru C, Bruix J: Prognosis of hepatocellular carcinoma: the BCLC staging classification. Semin Liver Dis 1999, 19:329-338

14. Harrison LE, Koneru B, Baramipour P, Fisher A, Barone A, Wilson D, Dela Torre A, Cho KC, Contractor D, Korogodsky M: Locoregional recurrences are frequent after radiofrequency ablation for hepatocellular carcinoma. J Am Coll Surg 2003, 197:759-764.

15. Njei B, Ditah I, Lim JK: Persistent racial disparities in survival among U.S. adults with hepatocellular carcinoma after liver transplantation: the paradox of all-cause and cause-specific mortality. Gastrointest Cancer Res 2013, 6(3):73-74

16. Mazzaferro V, Regalia E, Doci R, Andreola S, Pulvirenti A, Bozzetti F, Montalto F, Ammatuna M, Morabito A, Gennari L: Liver transplantation for the treatment of small hepatocellular carcinomas in patients with cirrhosis. N Engl J Med 1996, 334(11):693-699.

17. Bruix J, Sherman M: Management of hepatocellular carcinoma. Hepatology 2005, 42:1208-1236.

18. Llovet JM, Bruix J: Systematic review of randomized trials for unresectable hepatocellular carcinoma: chemoembolization improves survival. Hepatology 2003, 37:429-442.

19. Cammà C, Schepis F, Orlando A, Albanese M, Shahied L, Trevisani F, Andreone P, Craxi A, Cottone M: Transarterial chemoembolization for unresectable hepatocellular carcinoma: metaanalysis of randomized controlled trials. Radiology 2002, 224:47-54.

20. Lewis AL, Gonzalez MV, Leppard SW, Brown JE, Stratford PW, Phillips GJ, Lloyd AW: Doxorubicin eluting beads - 1: effects of drug loading on bead characteristics and drug distribution. J Mater Sci Mater Med 2007, 18:1691-1699.

21. Varela M, Real MI, Burrel M, Forner A, Sala M, Brunet M, Ayuso C, Castells L, Montañá X, Llovet JM, Bruix J: Chemoembolization of hepatocellular carcinoma with drug eluting beads: efficacy and doxorubicin pharmacokinetics. J Hepatol 2007, 46:474-481.

22. Takayasu K, Arii S, Ikai I, Kudo M, Matsuyama Y, Kojiro M, Makuuchi M, Liver Cancer Study Group of Japan: Overall survival after transcarterial lipiodol infusion chemotherapy with or without embolization for unresectable hepatocellular carcinoma: propensity score analysis. AJR Am J Roentgenol 2010, 194:830-837.

23. Zhao G-S, Liu Y, Zhang Y-W, Li C, Tang S-X, Zhou J, Liu S: Huaier granules combined with intraarterial chemoembolization for the treatment of hepatocellular carcinoma. Chin J Gen Surg 2013, 28(6):440-443.

doi:10.1186/1477-7819-12-300

Cite this article as: Liu et al: Complete remission of diffuse hepatocellular carcinoma in a young adult after GSP-TACE: a case report. World Journal of Surgical Oncology 2014 12:300.

\section{Submit your next manuscript to BioMed Central and take full advantage of:}

- Convenient online submission

- Thorough peer review

- No space constraints or color figure charges

- Immediate publication on acceptance

- Inclusion in PubMed, CAS, Scopus and Google Scholar

- Research which is freely available for redistribution 